Neurosurg Focus 13 (2):Article 14, 2002, Click here to return to Table of Contents

\title{
Black disc disease: a commentary
}

\author{
Setti S. Rengachary, M.D., and RaJu S. V. Balabhadra, M.D. \\ Department of Neurosurgery, Spine Surgery Service, Wayne State University School of Medicine, \\ Detroit Medical Center, Detroit, Michigan
}

\begin{abstract}
Internal disc disruption associated with axial back pain but not radicular pain is a disease entity that was recognized about two decades ago as a disorder that could potentially be treated by spinal fusion. In this article the authors describe the clinical syndrome, magnetic resonance imaging and discography findings of pathophysiological pain generation, and the available surgical options. Based on the current understanding of this disease entity, the optimum surgical procedure entails radical discectomy, anterior column support, adequate amounts of auto- or allograft bone, bone extenders and enhancers, and rigid stabilization of the motion segment.
\end{abstract}

KEY WORDS - disc degeneration • internal disc disruption - magnetic resonance imaging • discography $\bullet$ discogenic pain $・$ lumbar fusion

Lumbar DDD is manifest clinically by a spectrum of disorders, including disc extrusion with or without migrated fragment, disc protrusion, (central, paracentral, intraforaminal, or far-lateral) disc bulge, and internal disc disruption. Of these, frank disc rupture causing monoradiculopathy or cauda equina syndrome is a well-established entity. Very little, if any, controversy exists with regard to its clinical diagnosis or management, although there may be minor differences of opinion about the choice of options for treatment. In the past two decades, the syndrome of disc resorption without disc herniation has been recognized as a definable entity amenable to surgical treatment. ${ }^{11,12}$ Historically, disc rupture with monoradiculopathy was thought to be a clinical syndrome amenable to surgery, originating with the initial description of the syndrome by Mixter and Barr. ${ }^{30}$ Patients presenting with axial back-dominant pain but with minimal or absent radicular pain were not thought to be good candidates for surgical intervention. There have been advances in several related fields, including a better understanding of the anatomical, physiological, and biochemical features of pain generators in the intervertebral disc, refinements in the technique of lumbar discography, improved resolution in MR imaging, development of newer anterior approaches to the lumbar disc (open or laparoscopic), evolving concepts about the usefulness of bone morphogenetic proteins, and critical evaluations of surgery-related results following lumbosacral fusion. These advances are contributing to the rapid contemporary evolution in the understanding of discogenic pain syndrome.

Several terms have been applied to this discogenic pain syndrome and the differences are minor; these include

Abbreviations used in this paper: $\mathrm{DDD}=$ degenerative disc disease; $\mathrm{MR}=$ magnetic resonance; $\mathrm{PLIF}=$ posterior lumbar interbody fusion. trauma-induced internal disc disruptions, black disc disease, isolated disc resorption, and segmented instability.

\section{CLINICAL SYNDROME}

Discogenic back pain syndrome appears to be a disease of adulthood. Although disc disease is well recognized in teenagers and even younger children, the childhood syndrome is one of disc herniation at a single or multiple levels. The incidence of lumbosacral DDD is higher in young athletes such as gymnasts or ballet dancers, but in our experience, they present with disc herniation rather than black disc disease. This difference may be the result of age-related biochemical changes in the intervertebral disc.

The cardinal manifestation of internal disc disruption is back pain. Although a patient's description may seemingly suggest diffuse low-back pain, we have found that when specifically questioned and asked to run a finger horizontally across the back at the site of maximum pain, the accuracy of this pain localization matches that defined by MR imaging in approximately $80 \%$ of the cases. This observation may be related to the segmental nature of innervation of the anulus, which is the most pain-sensitive structure. ${ }^{23} \mathrm{O}^{\prime}$ Brien $^{35,36}$ has observed focal tenderness at the anterior lumbosacral region with transabdominal palpation. He attributed this to the rich innervation of the anterior anulus, which is irritated with internal disc disruption. His observation has not been validated by others because anterior abdominal palpation is not commonly practiced in the clinical setting in patients with low-back pain. The pain is characterized as mechanical, made worse with sitting, standing, pushing, pulling, bending, and twisting but relieved by recumbency. The pain may extend to the sacroiliac area, buttock, and back of the thigh but generally no farther. The pain may sometimes radiate to the groin or anterior thigh. Frank radicular pain is uncommon, but 


\section{S. S. Rengachary and R. S. V. Balabhadra}

we have encountered patients reporting radiating pain in the nerve root distribution but have found no evidence of objective root deficit; even if a deficit is present, it is a blunting to pinprick sensation, but invariably there is no motor weakness. Straight leg raising tests or sciatica-related stretch tests consistently show no signs of abnormality. When the aching pain extends to the posterior thigh, it may be difficult to differentiate from facet joint origin. The use of differential blocks of the disc and facets in patients with back pain syndrome, however, have shown a low incidence of facet disorder with discogenic pain. ${ }^{44}$

The onset of pain is generally gradual and insidious. Patients generally are not able to relate a specific event or determine a specific date of onset. The exception to this rule is a forceful fall in which the individual lands on the buttocks. We have observed graphic instances of this in cases of occupational injury (for example, with one leg dropping into a manhole not protected by a cover and the pelvis striking the ground). These cases may initially be treated as back sprains or back contusions, only to present years later with typical syndrome of internal disc disruption. Although direct loading injuries to the lumbar spine can explain the onset of internal disc disruption biomechanically, victims of motor vehicle accidents in whom this disorder is diagnosed have had a preexisting problem that is only aggravated by the accident. Loading injuries do not occur even in high-velocity accidents with the individual in the seated position.

\section{CAUSATIVE FACTORS}

Unquestionably, repetitive or continuous axial overloading is the key determinant in the pathogenesis of lumbosacral degenerative disease. Morbid obesity continues to be a major public health issue in the United States and, to a lesser extent, in other Western nations. The clinical triad in the obese individual is intractable low-back pain, bilateral knee pain, and flat feet with bilateral ankle pain. The primary pathological process is cartilaginous degeneration in the intervertebral discs and the cartilage in the knee joint. Although axial loading is the obvious factor implicated, accelerated degeneration due to fatty infiltration of cartilage may not be ruled out. It is unwise in this setting to consider surgical intervention until serious measures are undertaken for weight reduction. These may include sustained, systematic reduction in caloric intake under medical supervision, increased physical activity with a tailored exercise program, pharmacological therapy for appetite suppression and enhanced fat excretion, and, as a final resort, gastric bypass surgery. If the patient fails to participate in a weight-reduction program, it will be futile in most instances to consider back surgery.

Genetic factors have an influence in the incidence of the DDD. ${ }^{3}$ Defects in the DNA for collagen have been identified in family clusters predisposed to degenerative disc disease. Other genetic defects resulting in impaired proteoglycon synthesis are being explored. Videman, et al., ${ }^{46}$ noted that polymorphism associated with the vitamin D receptor gene correlated with intervertebral disc degeneration. Richardson, et al., ${ }^{41}$ confirmed, through an epidemiological survey, the presence of a familial disposition for back pain. Degenerative disorders involving family clusters tend to manifest as multilevel disc herniations at a younger age. Elfering, et al., ${ }^{14}$ noted a high incidence of disc degeneration in individuals working night shifts because of the relative dessication of the disc at night.

Occupation is a very important determinant. Workers performing typical repetitive work in an assembly line setting are prone to back problems, especially if the work involves repetitive bending, turning, and lifting. Jobs necessitating lifting and carrying heavy loads are associated with a high incidence of lumbar degenerative disease; examples include furniture movers, landscapers, and medical assistants working in nursing homes. Authors of epidemiological studies point to whole-body vibratory forces such as driving trucks, earthmovers, or tractors as contributing to low-back pain. . $^{18,40}$

Vigorous and compulsive athletic activities in a competitive setting predispose to accelerated degeneration of discs. ${ }^{1}$ Examples include weightlifting and gymnastics.

Cigarette smoking is implicated in DDD, but a direct link has not been proven.

\section{PAIN GENERATION}

It is crucial to understand and localize the DDD-related pain generator to tailor the surgical treatment and eliminate the source of pain. As stated previously, O'Brien ${ }^{35,36}$ has noted pain in the anterior anulus on direct palpation of the area transabdominally. In pioneering studies in performing lumbar laminectomy after injection of a local anesthetic Kuslich, et al., ${ }^{23}$ and others ${ }^{49}$ noted that anular fibrosis is the most pain-sensitive structure. Histopathological studies of cadaveric discs and those removed surgically have shown rich innervation of the anulus. The nerve terminals involved may be either somatic or autonomic. ${ }^{19,37,45}$ It is intriguing to observe that in the pathological disc there is more active sprouting of the nerve terminals than in a normal disc. ${ }^{10}$ Ashton and associates ${ }^{2}$ identified substance $\mathrm{P}$ in the vascular endothelium of the anulus fibrosus in excised discs. All of these observations indicate that total disc excision to eliminate all anular pain nerve endings should be part of a well-designed surgical procedure. This observation is also corroborated by the fact that patients who have undergone nondiscectomy posterior spinal fusion may continue to experience discogenic back pain despite demonstration of solid posterior fusion on neuroimaging studies. An ideal operation should eliminate the disc (the pain source) as well as motion.

\section{MAGNETIC RESONANCE IMAGING FINDINGS}

There are certain consistent MR imaging changes indicative of DDD, ${ }^{15,17,29,38,39}$ but the findings should always be interpreted in light of clinical presentation because it is impossible to differentiate symptomatic from incidental syndromes based on MR imaging studies alone. ${ }^{32}$ A defining characteristic is the decrease in signal intensity on $\mathrm{T}_{2}$ weighted sequences obtained in the nucleus pulposus compared with the adjacent disc (Fig. 1). The outline of the nucleus pulposus becomes irregular and the disc height decreases. An intense dotlike high-intensity signal in the posterior anulus signifies an anular tear. ${ }^{43}$ The cortical endplate and the adjacent marrow show changes in three steps, well described by Modic. ${ }^{31}$ 


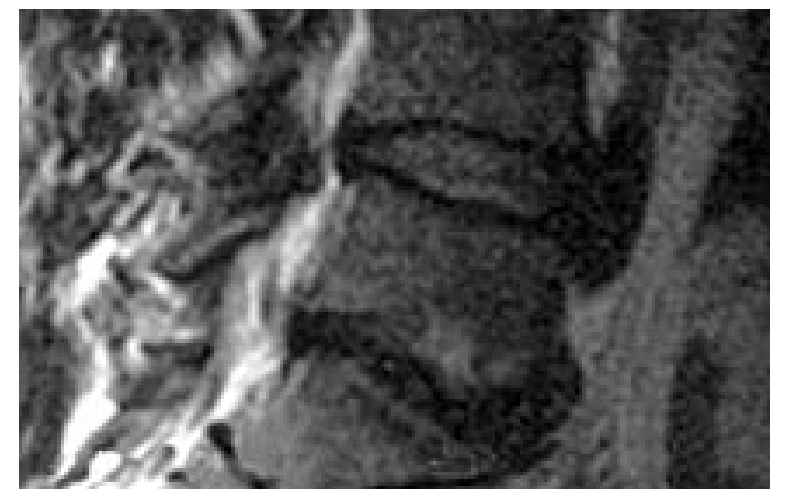

Fig. 1. Sagittal $\mathrm{T}_{2}$-weighted MR image demonstrating black disc disease at L5-S1.

\section{ROLE OF DISCOGRAPHY}

Although the role of provocative discography in the diagnosis of discogenic pain syndrome remains controversial, in the past 2 to 3 years its role has become better defined. ${ }^{1,4,9,28,33,47}$ The results are still somewhat operator dependent. Careful review of the patients' presenting complaints, their physical findings, and the information from other imaging studies should be undertaken. The targeted discs should be clearly identified before the study. No more than three discs should be injected during any single study. In our practice, we limit discography to two specific clinical settings: 1) a patient with credible pain, well-defined low-back tenderness, some objective signs of nerve root irritation, and yet no evidence of abnormality on MR imaging (in this setting, the suspected pathological disc is injected first and then the adjacent disc); and 2) a patient with a well-defined degenerative disc at one level with marginal changes in the immediately adjacent disc (one needs to determine if the second disc needs to be included in the fusion).

\section{PATIENT MANAGEMENT}

As a sound surgical principle, general conservative measures should be instituted first. These may include a long-term exercise program for conditioning, physical therapy with various modalities, a trial of epidural steroid injections, and a corset worn only when the patient is active. All of these physical measures are supplemented by pharmacological therapy involving nonsteroidal antiinflammatory drugs, muscle relaxers, and low-potency narcotic agents. A patient's lifestyle or vocation may have to be modified to avoid repetitive injury. Restrictions at the worksite and establishment of an ergonomic environment in the workplace, with the assistance of an occupational therapist, might help reduce the likelihood of repetitive injury.

Failure of conservative treatment over a period of 3 to 6 months heralds the need for surgical treatment. Table 1 provides a summary of the surgical choices available today. The number of choices is increasing with the introduction of percutaneous placement of pedicle screws and the impending approval of bone morphogenetic protein for clinical use. The choice of surgical procedure is also governed by published results pertaining to long-term fol-
TABLE 1

Surgical options in black disc disease*

ALIF alone

ALIF w/ transfacetal screw

ALIF w/ pedicle screw stabilization (open or percutaneous)

PLIF w/ pedicle screw stabilization

transforaminal interbody fusion with pedicle screw stabilization

* ALIF = anterior lumbar interbody fusion.

low up in patients who have undergone surgery via various techniques.

Cloward ${ }^{8}$ pioneered the technique of PLIF in which structural allograft was used. Although he reported 80 to $90 \%$ fusion rates without the use of pedicle screws, others ${ }^{6}$ have not been able to reproduce his success rate. $\operatorname{Lin}^{25}$ and $\mathrm{Ma}^{27}$ have refined the PLIF technique. Poor success rates have led to other techniques. Kuslich, et al., ${ }^{22}$ introduced the use of threaded cages, but analysis of recent results indicates that there is high failure rate with stand-alone cages introduced anteriorly or posteriorly, unless they are supplemented by pedicle screw stabilization. Anterior interbody fusion with femoral ring in single-level disease yields a success rate of 80 to $90 \%$, but the rate drops precipitously in two-level procedures unless supplemented by posterior stabilization. The Harrms transforaminal fixation technique ${ }^{41}$ involves the unilateral removal of facet joint, radical discectomy, anterior column support in which cages are supplemented by bone, and pedicle screw stabilization. This is a viable alternative to combined $360^{\circ}$ decompression and fusion and is currently our preferred option for black disc disease. The choice of surgical tech-

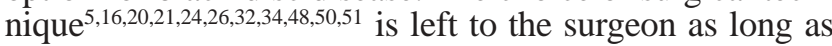
the following principles are adhered to: near-total excision of the intervertebral disc; placement of spacer to maintain anterior column support and lordosis; use of adequate bone graft, bone extender, and bone enhancers; and surgical stabilization.

\section{References}

1. Adams MA, Dolan P, Hutton WC: The stages of disc degeneration as revealed by discograms. J Bone Joint Surg Br 68: 36-41, 1986

2. Ashton IK, Walsh DA, Polak JM, et al: Substance P in intervertebral discs. Binding sites on vascular endothelium of the human annulus fibrosus. Acta Orthop Scand 65:635-639, 1994

3. Battie MC, Videman T, Gibbons LE, et al: 1995 Volvo Award in clinical sciences. Determinants of lumbar disc degeneration. A study relating lifetime exposures and magnetic resonance imaging findings in identical twins. Spine 20:2601-2612, 1995

4. Bernard TN Jr: Lumbar discography followed by computed tomography. Refining the diagnosis of low-back pain. Spine 15: 690-707, 1990

5. Blumenthal SL, Baker J, Dossett A, et al: The role of anterior lumbar fusion for internal disc disruption. Spine 13:566-569, 1988

6. Brantigan JW: Pseudarthrosis rate after allograft posterior lumbar interbody fusion with pedicle screw and plate fixation. Spine 19:1271-1280, 1994

7. Buirski G, Silberstein M: The symptomatic lumbar disc in patients with low-back pain. Magnetic resonance imaging appearances in both a symptomatic and control population. Spine 18: 1808-1811, 1993 


\section{S. S. Rengachary and R. S. V. Balabhadra}

8. Cloward RB: Lesions of the intervertebral disks and their treatment by interbody fusion methods. The painful disk. Clin Orthop 27:51-77, 1963

9. Colhoun E, McCall IW, Williams L, et al: Provocation discography as a guide to planning operations on the spine. $\mathbf{J}$ Bone Joint Surg Br 70:267-271, 1988

10. Coppes MH, Marani E, Thomeer RT, et al: Innervation of "painful" lumbar discs. Spine 22:2342-2350, 1997

11. Crock HV: Internal disc disruption. A challenge to disc prolapse fifty years on. Spine 11:650-653, 1986

12. Crock HV: A reappraisal of interverebral disc lesions. Med J Aust 1:983-989, 1970

13. Deusinger RH: Biomechanical considerations for clinical application in athletes with low back pain. Clin Sports Med 8: 703-713, 1989

14. Elfering A, Semmer N, Birkhofer D, et al: Young investigator award 2001 winner: Risk factors for lumbar disc degeneration: a 5-year prospective MRI study in asymptomatic individuals. Spine 27:125-134, 2002

15. Gibson MJ, Buckley J, Mawhinney R, et al: Magnetic resonance imaging and discography in the diagnosis of disc degeneration. A comparative study. J Bone Joint Surg Br 68: 369-373, 1986

16. Haid RW Jr, Dickman CA: Instrumentation and fusion for discogenic disease of the lumbosacral spine. Neurosurg Clin $\mathbf{N}$ Am 4:135-148, 1993

17. Horton WC, Daftari TK: Which disc as visualized by magnetic resonance imaging is actually a source of pain? A correlation between magnetic resonance imaging and discography. Spine 17 (Suppl 6):S164-S171, 1992

18. Hulshof C, van Zanten BV: Whole-body vibration and lowback pain. A review of epidemiologic studies. Int Arch Occup Environ Health 59:205-220, 1987

19. Jaffray D, O'Brien JP: Isolated intervertebral disc resorption. A source of mechanical and inflammatory back pain? Spine 11: 397-401, 1986

20. Kozak JA, Heilman AE, O'Brien JP: Anterior lumbar fusion options. Technique and graft materials. Clin Orthop 300: 45-51, 1994

21. Kozak JA, O'Brien JP: Simultaneous combined anterior and posterior fusion. An independent analysis of a treatment for the disabled low-back pain patient. Spine 15:322-328, 1990

22. Kuslich SD, Ulstrom CL, Griffith SL, et al: The Bagby and Kuslich method of lumbar interbody fusion. History, techniques, and 2-year follow-up results of a United States prospective, multicenter trial. Spine 23:1267-1279, 1998

23. Kuslich SD, Ulstrom CL, Michael CJ: The tissue origin of low back pain and sciatica: a report of pain response to tissue stimulation during operations on the lumbar spine using local anesthesia. Orthop Clin North Am 22:181-187, 1991

24. Lee CK, Langrana NA: Lumbosacral spinal fusion. A biomechanical study. Spine 9:574-581, 1984

25. Lin PM: Posterior lumbar interbody fusion technique: complications and pitfalls. Clin Orthop 193:90-102, 1985

26. Linson MA, Williams H: Anterior and combined anteroposterior fusion for lumbar disc pain. A preliminary study. Spine 16: 143-145, 1991

27. Ma GW: Posterior lumbar interbody fusion with specialized instruments Clin Orthop 193:57-63, 1985

28. McNally DS, Shackleford IM, Goodship AE, et al: In vivo stress measurement can predict pain on discography. Spine 21: 2580-2587, 1996

29. Milette PC, Fontaine S, Lepanto L, et al: Differentiating lumbar disc protrusions, disc bulges, and discs with normal contour but abnormal signal intensity. Magnetic resonance imaging with discographic correlations. Spine 24:44-53, 1999

30. Mixter WJ, Barr JS: Rupture of the intervertebral disc with in- volvement of the spinal canal. N Engl J Med 211:210-215, 1934

31. Modic MT: Degenerative disc disease and back pain. Magn Reson Imaging Clin N Am 7:481-491, 1999

32. Montesano PX, Magerl F, Jacobs RR, et al: Translaminar facet joint screws. Orthopedics 11:1393-1397, 1988

33. Nachemson A: Lumbar discography--where are we today? Spine 14:555-557, 1989

34. Nachemson A, Zdeblick TA, O'Brien JP: Lumbar disc disease with discogenic pain. What surgical treatment is most effective? Spine 21:1835-1838, 1996

35. O'Brien JP: Anterior spinal tenderness in low-back pain syndromes. Spine 4:85-88, 1979

36. O'Brien JP: Should backache be treated with spinal fusion? Spinal fusion is the only treatment for discogenic pain. BMJ 312: 38-39, 1996

37. Palmgren T, Gronblad M, Virri J, et al: Immunohistochemical demonstration of sensory and autonomic nerve terminals in herniated lumbar disc tissue. Spine 21:1301-1306, 1996

38. Pech P, Haughton VM: Lumbar intervertebral disk: correlative MR and anatomic study. Radiology 156:699-701, 1985

39. Pfirrmann CW, Metzdorf A, Zanetti M, et al: Magnetic resonance classification of lumbar intervertebral disc degeneration. Spine 26: 1873-1878, 2001

40. Pope MH, Hansson TH: Vibration of the spine and low back pain. Clin Orthop 279:49-59, 1992

41. Richardson JK, Chung T, Schultz JS, et al: A familial predisposition toward lumbar disc injury. Spine 22:1487-1493, 1997

42. Rosenberg WS, Mummaneni PV: Transforaminal lumbar interbody fusion: technique, complications, and early results. Neurosurgery 48:569-575

43. Schellhas KP, Pollei SR, Gundry CR, et al: Lumbar disc highintensity zone. Correlation of magnetic resonance imaging and discography. Spine 21:79-86, 1996

44. Schwarzer AC, Aprill CN, Derby R, et al: The relative contributions of the disc and zygapophyseal joint in chronic low back pain. Spine 19:801-806, 1994

45. Suseki K, Takahashi Y, Takahashi K, et al: Sensory nerve fibers from lumbar intervertebral discs pass through rami communicantes. A possible pathway for discogenic low back pain. J Bone Joint Surg Br 80:737-742, 1998

46. Videman T, Leppavuori J, Kaprio J, et al: Intragenic polymorphisms of the vitamin D receptor gene associated with intervertebral disc degeneration. Spine 23:2477-2485, 1998

47. Wetzel FT, LaRocca SH, Lowery GL, et al: The treatment of lumbar spinal pain syndromes diagnosed by discography. Lumbar arthrodesis. Spine 19:792-800, 1994

48. Wood GW II, Boyd RJ, Carothers TA, et al: The effect of pedicle screw/plate fixation on lumbar/lumbosacral autogenous bone graft fusions in patients with degenerative disc disease. Spine 20:819-830, 1995

49. Yoshizawa H, O'Brien JP, Smith WT, et al: The neuropathology of intervertebral discs removed for low-back pain. J Pathol 132:95-104, 1980

50. Zdeblick TA: The treatment of degenerative lumbar disorders. A critical review of the literature. Spine 20 (Suppl 24): 126S-137S, 1995

51. Zdeblick TA, Hanley EN Jr, Sonntag VK, et al: Indications for lumbar spinal fusion introduction. 1995 Focus Issue Meeting on Fusion. Spine 20 (Suppl 24):124S-125S, 1995

Manuscript received June 17, 2002.

Accepted in final form July 11, 2002.

Address reprint requests to: Setti S. Rengachary, M.D., Department of Neurosurgery, 4201 St. Antoine, Suite 6E, Detroit, Michigan 48201. email: srengachary @ neurosurgery.wayne.edu. 